\title{
Radiological Intervention and Imaging Procedures in Management of Patients with Malignant Obstructive Jaundice
}

\author{
ASHRAF M. DAWOUD, M.Sc.*; HAZEM M. OMAR, M.D.**; MOHAMMED A. AMIN, M.D.* and \\ ABDELMONEM NOOMAN, M.D.* \\ The Department of Radio-Diagnosis \& Medical Imaging, Faculty of Medicine, Tanta University* and \\ Liver Institute, Menofia University**
}

\begin{abstract}
Background: Malignant biliary obstruction has a bad prognosis and adverse effect on the quality of life, with most of those patients are inoperable at time of diagnosis. Patients who underwent whipple operation may develop anastomotic site (choledocho-jujenostomy) stenosis with subsequent elevated bilirubin level and related complications.

Aim of Study: This prospective study will be conducted to evaluate the efficacy of different modalities of interventional radiological and imaging procedures as Percutaneous Trans hepatic Cholangiography (PTC), Percutaneous Trans hepatic Drainage (PTD) and biliary stenting in management of patients with malignant obstructive jaundice.
\end{abstract}

Patients and Methods: This study was conducted on 30 patients (19 males and 11 females) with mean age of 56 years, 28 of 30 patients $(93.3 \%)$ are non operable and the other 2 of 30 patients $(6.7 \%)$ operated patients for choledochojujenostomy stenosis were subjected to intervention techniques. 10 of 30 patients $(33.3 \%)$ underwent percutaneous external biliary drainage, 15 of 30 patients $(50 \%)$ underwent percutaneous stent insertion ( 8 of 30 patients $(26.7 \%)$ with metallic stents \& 7 of 30 patients $(23.3 \%)$ with plastic stents), 3 of 30 patients $(10 \%)$ underwent internal external drainage and 2 of 30 patients $(6.66 \%)$ underwent biliary drainage through combined (randez-voux) technique.

Results: High success rate (86.6\%) with reduction of total bilirubin level was observed in metallic stenting group of patients.

Conclusion: Biliary intervention procedures help to reduce high bilirubin level, bypass obstruction level and help in dilatation of post-operative stenosis site.

Keywords: Biliary system - Malignant obstructive jaundice.

\section{Introduction}

THE biliary system consists of the organs and ducts (bile ducts, gallbladder, and associated struc-

Correspondence to: Dr. Ashraf M. Dawoud, The Department of Radio-Diagnosis \& Medical Imaging, Faculty of Medicine, Tanta University tures) that are involved in the production and transportation of bile $[\mathbf{1 , 2}]$.

There are multiple causes of biliary obstruction as gall stones, malignant obstruction by hepatic, pancreatic or common bile duct tumours, also inflammation of bile ducts may cause biliary obstruction $[3,4]$.

Diagnosis of obstruction is achieved by non invasive and invasive procedures: Non invasive procedures include ultrasonography and MRCP, the invasive procedures include ERCP and PTC which has diagnostic and therapeutic roles [5]

PTC is predominantly now performed as a therapeutic technique. If the biliary system is obstructed, PTC may be used to perform biliary drainage until a more permanent solution for the obstruction is performed (e.g. surgery) [6] .

Additionally, self expanding metallic stents can be placed across malignant biliary strictures to allow palliative drainage. Percutaneous placement of metallic stents can be utilized when therapeutic ERCP has been unsuccessful, two types of biliary stent are used as metal and plastic types $[7,8]$

Aim of this study is to evaluate efficacy of interventional radiological procedures in management of patient with malignant obstructive jaundice.

\section{Patients and Methods}

This study included 30 patients, 19 male $(63.3 \%)$ and 11 female (3 6.6\%) with age ranging from 37 to 75 years with mean age of 56 years diagnosed with malignant obstructive jaundice attending to Radiodiagnosis Department at Tanta University and Radiodiagnosis Department at Liver Institute, Menofia University in the period between January 
2018 and December 2018. Ethics Committee approval and informed consent were obtained.

\section{Inclusion criteria:}

1- Patients with malignant obstructive jaundice who refused surgical operation.

\section{2- Failed ERCP.}

3- Inoperable patients as patients with irresectable tumor, patients with cardiac dysfunction or renal impairment.

4- Pre-operative for patients with malignant obstructive jaundice fit for operation and postoperative for management of complications.

\section{Exclusion criteria:}

1- Pregnancy (as there is high risk of radiation exposure).

2- Patients with bleeding disorders.

All the patients were dealt with in the following manner:

1- Full history taking.

2- Clinical examination.

3- Laboratory investigations: Liver function tests, renal function tests, $\mathrm{CBC}$, prothrombin (time, concentration and INR) and tumour markers (AFP, CA19.9 and CEA).

\section{4- Radiological and imaging assessment:}

**Routine abdominal ultrasonography, Triphasic Computed Tomography (CT) study of the abdomen for 18 patients, MRCP with complementary MRI abdomen for 22 patients.

\section{Intervention radiological techniques:}

Intervention radiological techniques for malignant obstructive jaundice patients were done in the Cath-lab Unit on Philips angiography apparatus. The following different interventional radiological techniques were done to our patients guided by their diagnosis, clinical state, laboratory investigations and strategy of management.

\section{1- External biliary drainage for 10 of 30 patients} $(33.3 \%)$.

2- Internal-external biliary drainage for 3 of 30 patients (10\%).

3- Biliary stenting for 15 of 30 patients (50\%), 8 of 30 patients with metallic stents $(26.7 \%)$ and 7 of 30 patients $(23.3 \%)$ with plastic stents.

4- Combined (Randez-voux) technique in 2 of 30 patients $(6.7 \%)$ (Table 5).
Under complete aseptic technique and local anaesthesia puncture of the dilated biliary radical using Chipa needle (18G) was done with the ultrasonography guidance in 18 of 30 patients $(60 \%)$ or cone beam CT guidance in 12 of 30 patients (40\%), passage of bile through the Chipa needle indicates successful puncture of the dilated biliary radical then insertion of $6 \mathrm{~F}$ sheath then cholangiogram was done using non inonic contrast media (Ultravest $370 \mathrm{mg} / \mathrm{ml}$ ).

1-Percutaneous external biliary drainage: Was done in 10 of 30 patients (33.3\%), this technique was done after doing cholagiogram (PTC) and revealed a very tight obstruction and a 4F Copra catheter over a 0.035 inch guide wire failed to bypass the obstruction, then withdrawal of the guide wire and insertion of a 0.035 inch stiff guide wire through the Copra catheter then withdrawal of both the Copra catheter and the introducer sheath. A 10F Pigtail catheter was inserted through the stiff guide wire above the level of obstruction after doing dilatation of the track using 8 and $10 \mathrm{~F}$ dilators, then the Pigtail catheter fixed to the skin by sutures.

2- Percutaneous internal-external biliary drainage: Was done in 3 of 30 patients $(10 \%)$. This method had the same technique as external biliary drainage but in this situation we could bypass the level of obstruction by the guide wire and the 4F Copra catheter over it and passing to the duodenum through the papilla then $10 \mathrm{~F}$ Pigtail catheter was inserted in the duodenum through the papilla after doing small holes through the pigtail proximal to the level of obstruction to act as internal external biliary drain and fixed to the skin by sutures.

3-Biliary stenting: Biliary stenting was done in 15 of 30 patients $(50 \%)$ :

A- Metallic biliary stenting: Was done in 8 of 30 patients $(26.6 \%)$. This technique had the same steps as external and internal external biliary drainage but when guide wire can bypass the obstruction in these patients, 4F Copra catheter was used to traverse the stricture over it, then withdrawal of the guide wire and insertion of stiff guide wire through the catheter then withdrawal of both the catheter and the sheath. A self-expandable stent of $10 \mathrm{~mm}$ diameter and variable lengths according to length of stricture segment was introduced along the stricture segment and then inserted in the proper position. Then balloon dilatation along the length of metallic stent using balloon of $4 \mathrm{~cm}$ length and $10 \mathrm{~mm}$ diameter for expansion of the site of stricture along stent after insertion by using inflator. PTC was done through the sheath to examine the proper position and patency of the stent. 
B- Plastic biliary stenting: Was done in 7 of 30 patients $(23.3 \%)$. In these patients the entry tract was dilated by serial dilators to the diameter of the stent. Plastic stent was inserted over the guide wire and inner $7-8 \mathrm{~F}$ catheter of stiffener and pushed by pusher which is of the same caliber of the stent. The stent was pushed so that its proximal end lies above the obstruction and its distal end below it. After that the guide wire and pusher were removed and the inner $7 \mathrm{~F}$ catheter was pulled above the stent and a control contrast examination was done to confirm stent position and patency.

4- Combined technique (Randez vous): This technique was done in 2 of 30 patients $(6.6 \%)$. This technique had the same steps as internal external biliary drainage till the guide wire bypassing the obstruction and reaching the duodenum through the papilla then the endoscope (ERCP) was introduced into the duodenum and catching the wire and complete the procedure of biliary drainage.

\section{Statistical methodology:}

Analysis of the data was performed by: Statistical Program of Social Science (SPSS), description of quantitative variables in the form of mean and Standard Deviation (SD), description of qualitative variables in the form of number and percentage, comparison of quantitative variables was confirmed by using paired $t$-test to compare data in the same group, one way ANOVA (analysis of variants) test to compare more than two groups as regard quantitative variable and $p$-valve ( $p>0.05$ insignificant, $p<0.05$ significant).

\section{Results}

Patients were already diagnosed with obstructive jaundice due to malignant cause, 12 of them were diagnosed to have pancreatic head cancer representing $40 \%$ of the patients, 8 of them were diagnosed with cholangicarcinoma (central and peripheral types) $26.6 \%, 4$ were diagnosed with periampullary carcinoma $13.3 \%, 4$ with enlarged porta hepatis lymph node $13.3 \%$ and the last two were diagnosed with hepatic metastasis $6.6 \%$ (Table 1).

Table (1): Causes of malignant obstructive jaundice among the studied patients.

\begin{tabular}{lll}
\hline Type of tumor & $\mathrm{N}$ & $\%$ \\
\hline Cancer head of pancreas & 12 & 40 \\
Cholangiocarcinoma & 8 & 26.6 \\
Periampullary carcinoma & 4 & 13.3 \\
Porta-Hepatis enlarged lymph nodes & 4 & 13.3 \\
Hepatic metastasis & 2 & 6.6 \\
\hline
\end{tabular}

According to the degree of biliary dilatation in our study groups, 3 patients showed minimal biliary dilatation (10\%), 5 patients showed mild degree (16.7\%), 13 patients showed moderate degree (43.3\%) and the last 9 patients showed marked degree of biliary dilatation (30\%) (Table 2).

Table (2): Degree of biliary dilatation among the studied patients.

\begin{tabular}{lcl}
\hline Degree & Number & $\%$ \\
\hline Minimal & 3 & 10 \\
Mild & 5 & 16.7 \\
Moderate & 13 & 43.3 \\
Marked & 9 & 30 \\
\hline
\end{tabular}

According to level of biliary obstruction, 2 of our study group patients were at the intrahepatic level $(6.7 \%), 8$ patients were at porta hepatis level (26.7\%), 2 patients were at proximal CBD level (6.7\%), 14 patients were at the level of distal CBD $(46.6 \%)$ and the last 4 patients were at the periampullary level (13.3\%) (Table 3).

Table (3): Level of biliary obstruction among the studied patients.

\begin{tabular}{lcl}
\hline Level & Number & $\%$ \\
\hline Intrahepatic & 2 & 6.7 \\
Portahepatis & 8 & 26.7 \\
Proximal CBD & 2 & 6.7 \\
Distal CBD & 14 & 46.6 \\
Periampullary & 4 & 13.3 \\
\hline
\end{tabular}

Patients underwent different interventional techniques:

1- Percutenous transhepatic external biliary drainage: Was done in 10 patients:

- Failure to bypass biliary stricture in 6 patients.

- Pre-operative for symptomatic relief in 2 patients who underwent whipple operation.

- Lack of financial support or patient's refusal to complete the procedure in 2 patients.

2- Percutenous metallic stenting: Was done in 8 patients:

- Six patients of them were unfit for operation.

- The other 2 with post-operative (whipple operation) choledocho-jujenostomy stricture.

3- Percutenous plastic stenting: Was done in 7 patients.

4- Internal-external drainage: Was done in 3 patients.

5- Randez vous technique: Was done in 2 patients. 
Table (4): Frequency of interventional procedures for study groups.

\begin{tabular}{|c|c|c|}
\hline & $\mathrm{N}=30$ & $\%$ \\
\hline Percutaneous external drainage (Group 1) & 10 patients & 33.3 \\
\hline Percutaneous metallic stenting (Group 2) & 8 patients & 26.7 \\
\hline Percutaneous plastic stenting (Group 3) & 7 patients & 23.3 \\
\hline Internal \& external drainage & 3 patients & 10 \\
\hline Rendez vous technique & 2 patients & 6.7 \\
\hline
\end{tabular}

Follow-up of the patients after the procedure was done by laboratory investigation (total bilirubin level).

We choosed the 15 day total bilirubin level as an indicator of therapeutic success.

Among different groups in our study the lowest mean total bilirubin level 15 days after drainage was achieved with metallic stenting $(3.8 \mathrm{mg} / \mathrm{ml})$, while the highest mean total bilirubin level 15 days after drainage was seen in percutaneous external drainage $(10 \mathrm{mg} / \mathrm{dl})$.

Table (5): Comparison of total bilirubin level before and after procedure among different studied patients.

\begin{tabular}{|c|c|c|c|c|}
\hline & $\begin{array}{c}\text { Total } \\
\text { Bilirubin } \\
\text { before } \\
\text { Mean (SD) } \\
(\mathrm{mg} / \mathrm{dl})\end{array}$ & $\begin{array}{c}\text { Total } \\
\text { Bilirubin } \\
\text { after } \\
\text { Mean (SD) } \\
\text { (mg/dl) }\end{array}$ & $\begin{array}{l}t- \\
\text { test }\end{array}$ & $p$-value \\
\hline $\begin{array}{l}\text { - External } \\
\text { drainage } \mathrm{N}=10\end{array}$ & $24.5(5.3)$ & $6.2(3.1)$ & 12 & $p<0.05^{*}$ \\
\hline \multicolumn{5}{|l|}{ Biliary stenting: } \\
\hline - Metallic $N=8$ & $17.02(2.7)$ & $3.8(1.09)$ & 14.5 & $p<0.01 * *$ \\
\hline - Plastic $\mathrm{N}=7$ & $18.3(4.1)$ & $4.9(3.8)$ & 4.5 & $p<0.05^{*}$ \\
\hline $\begin{array}{l}\text { - Internal-external } \\
\text { drainage } \mathrm{N}=3\end{array}$ & $16.4(3.2)$ & $10(4.3)$ & 10.7 & $p<0.01 * *$ \\
\hline $\begin{array}{l}\cdot \text { Rendez vout } \\
\mathrm{N}=2\end{array}$ & $15.3(4.5)$ & $6.2(4.4)$ & 10.2 & $p<0.01 * *$ \\
\hline
\end{tabular}

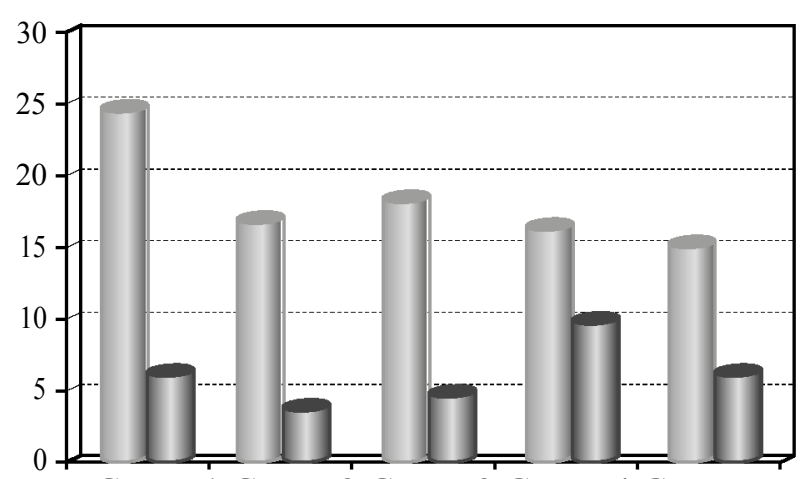

Group 1 Group 2 Group 3 Group 4 Group 5

Bilirubin level before

Bilirubin level after

Fig. (1): Mean total bilirubin level before and after intervention in different studied groups.
The highest rate of complications was among the percutaneous drainage group and the commonest occurring complication in the study was hemobillia.

Table (6): Frequency of complications among different studied groups.

$\begin{array}{llll} & \mathrm{N} \% \mathbf{o} & \\ \begin{array}{l}\text { Percutaneous external } \\ \text { drainage } N=10:\end{array} & & \\ \quad+\mathrm{ve} & 3 & 30 & \text { - Hemobillia } \\ \text {-ve } & 7 & 70 & \text { - Dislodgement }\end{array}$

Percutaneous metallic

stent $N=8$ :

$\begin{array}{llll}+\mathrm{ve} & 1 & 12.5 & \text { Cholangitis } \\ -\mathrm{ve} & 7 & 87.5 & \end{array}$

Internal \& external

drainage $N=3$ :

$\begin{array}{lll}+\mathrm{ve} & 0 & 0 \\ -\mathrm{ve} & 3 & 100\end{array}$

Percutenous plastic stent $N=7$ :

$\begin{array}{llll}+\mathrm{ve} & 2 & 28.5 & \text { Stent occlusion } \\ -\mathrm{ve} & 5 & 71.6 & \text { Cholangitis }\end{array}$

Rendez vous technique

$N=2$ :

\begin{tabular}{lll}
$+\mathrm{ve}$ & 0 & 0 \\
$-\mathrm{ve}$ & 2 & 100 \\
\hline$* *+\mathrm{ve}{ }^{*}$ Complications. & \\
$* *-\mathrm{ve}{ }^{*}$ No complications. &
\end{tabular}

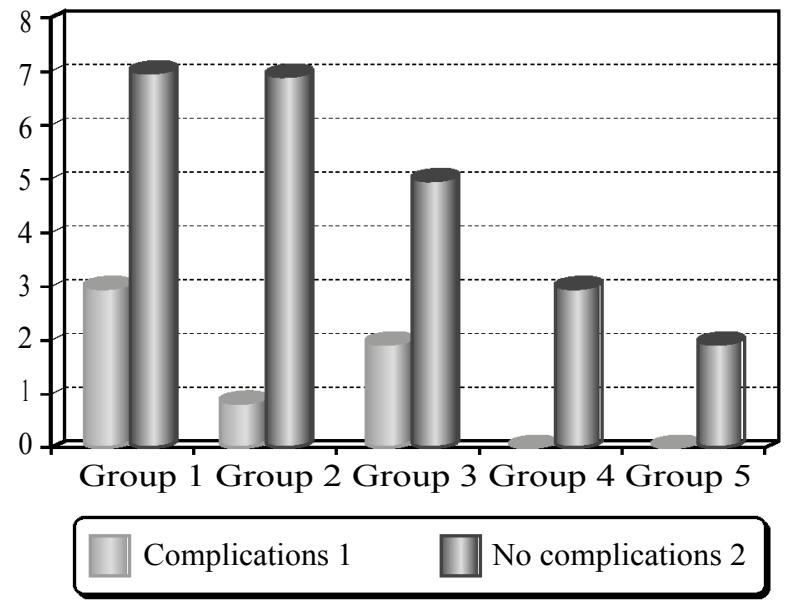

Fig. (2): Frequency of complications among different interventional procedures.

\section{Illustrated cases:}

Fig. No. (4):

- Male patient 64 years old diagnosed to have periampullary carcinoma.

- Total bilirubin level reached $19 \mathrm{mg} / \mathrm{dl}$.

- Internal-external drainage by a $10 \mathrm{~F}$ Pigtail catheter was done. 


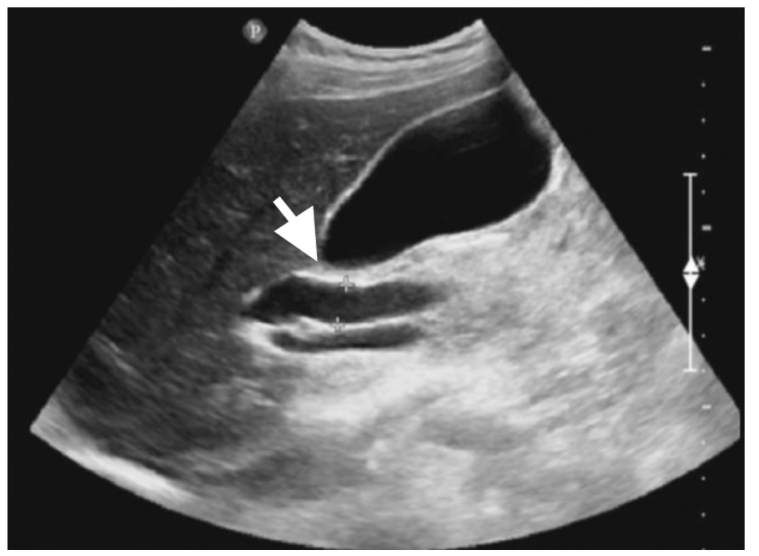

(A)

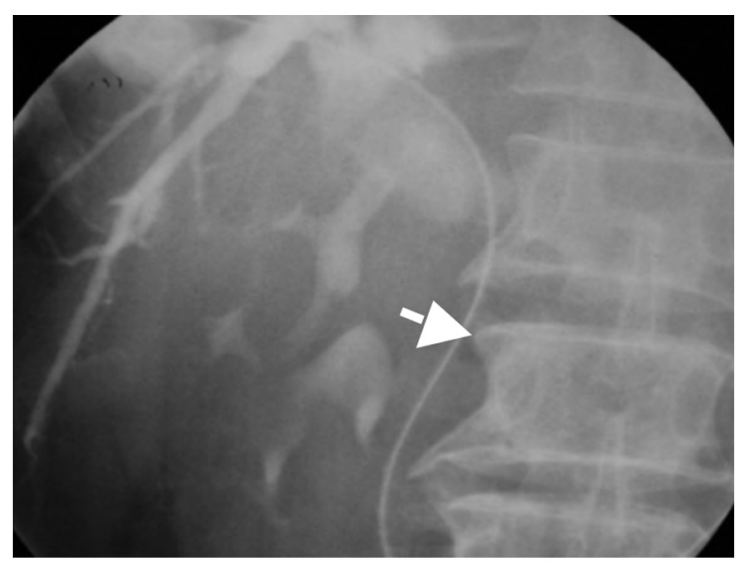

(C)

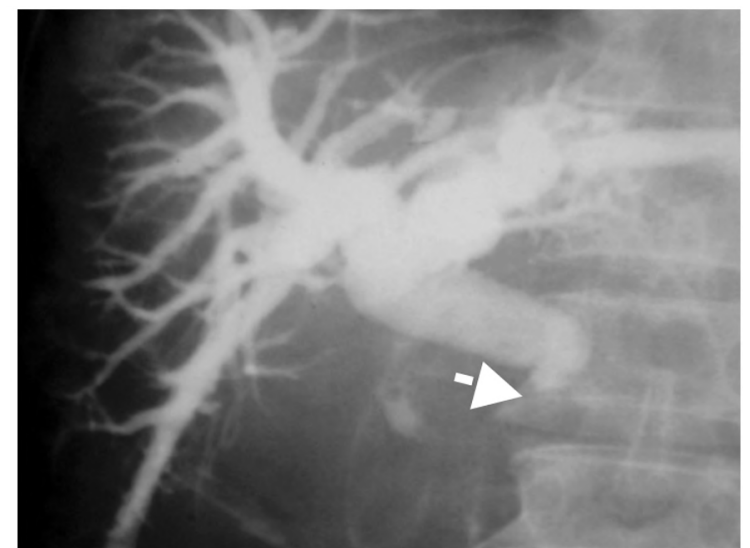

(B)

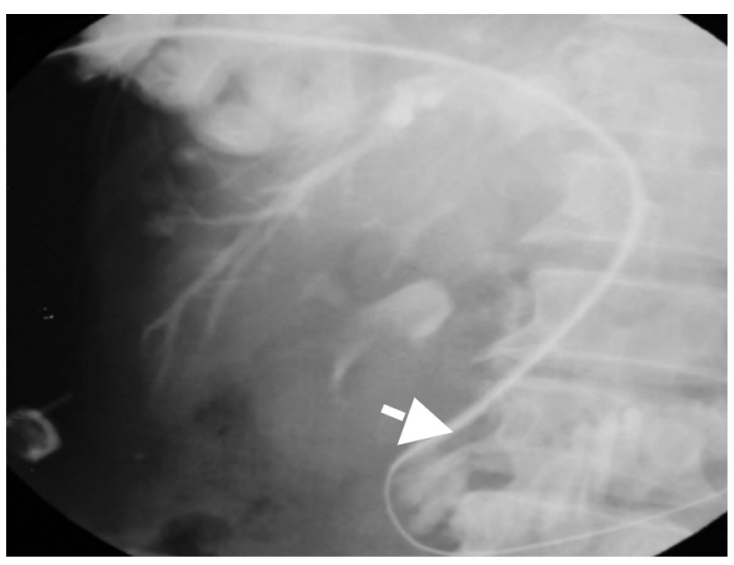

(D)

(E)

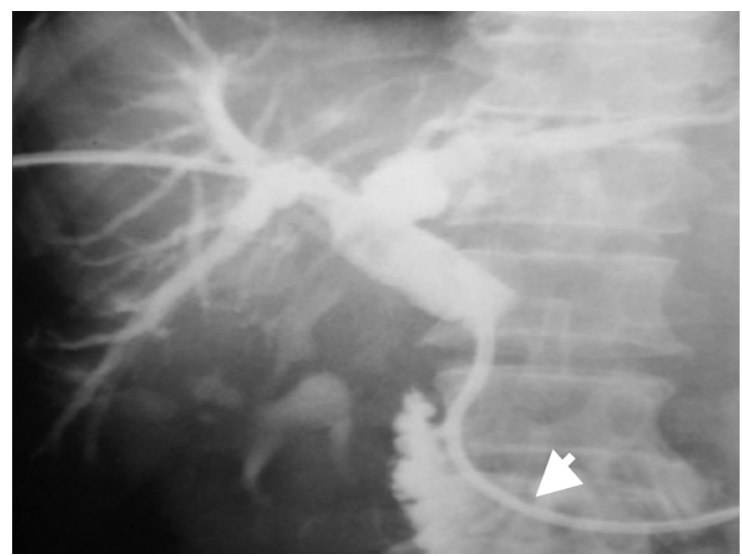

Fig. (4): (A) Ultrasonography showing dilated CBD calibre reaching $11 \mathrm{~mm}$ (arrow) with no detectable masses or stones inside its lumen. (B) PTC from a right sided approach showed dilated IHBR and CBD till abrupt cut-off of the contrast at its distal end (arrow). (C) A guide wire succeeded to cross the stricture into the duodenum (arrow). (D) A 10F Pigtail catheter passing through the stricture over the siff guide wire (arrow). (E) Inserted internal-external 10F pigtail catheter with free contrast flow into the duodenum (arrow). 
Fig. No. (5):

- Male patient 68 years old diagnosed to have Periampullary Carcinoma.

- Percutaneous plastic stent was inserted via right duct approach.

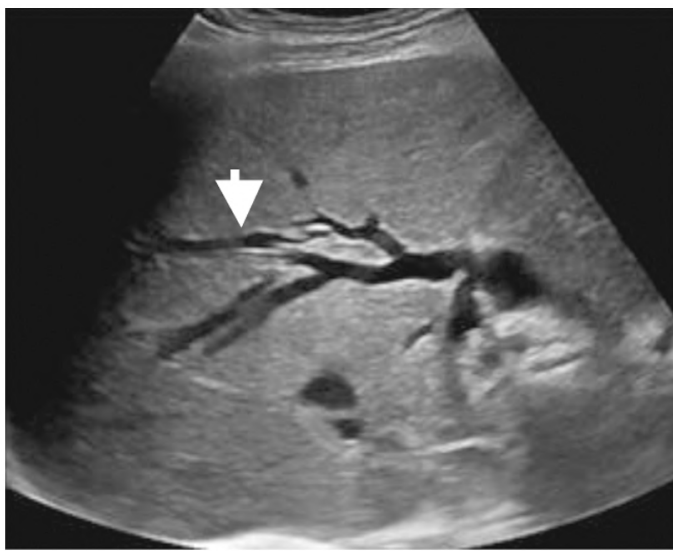

(A)

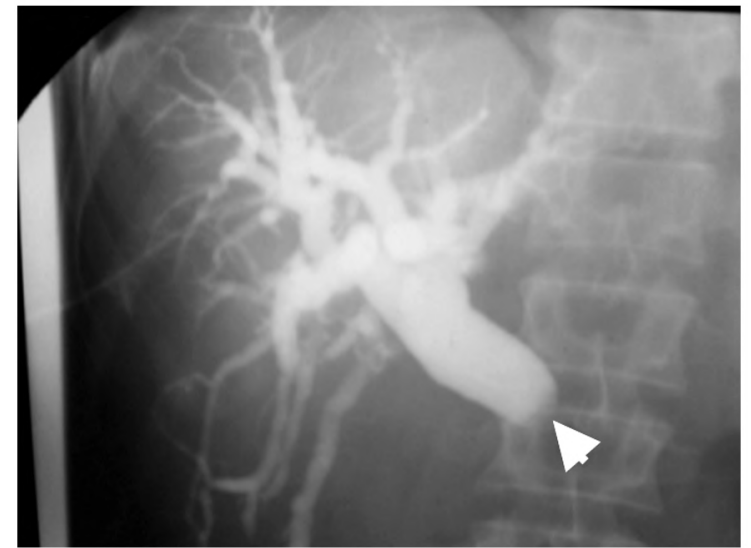

(C)

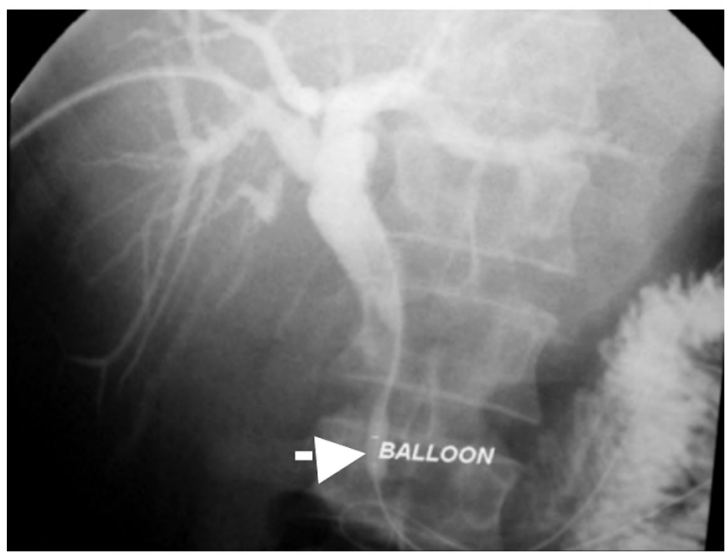

(E)

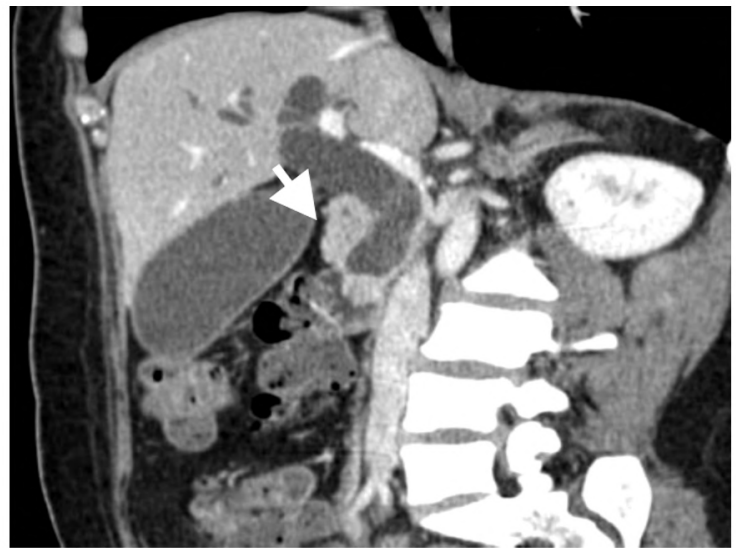

(B)

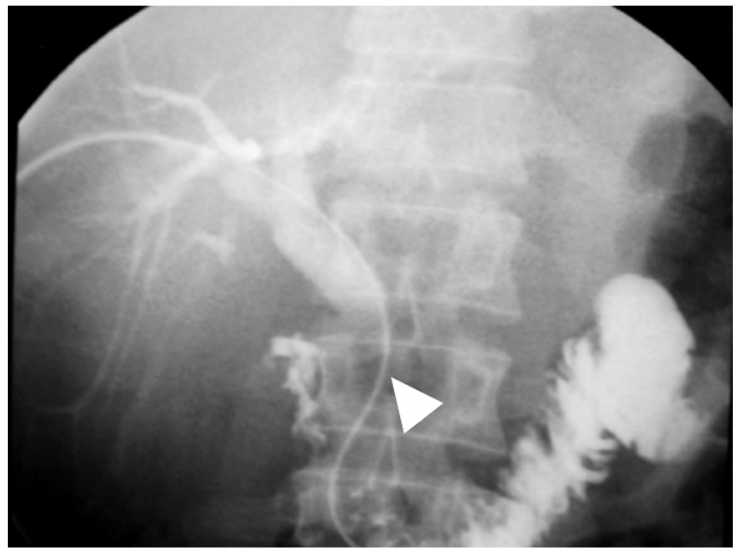

(D)

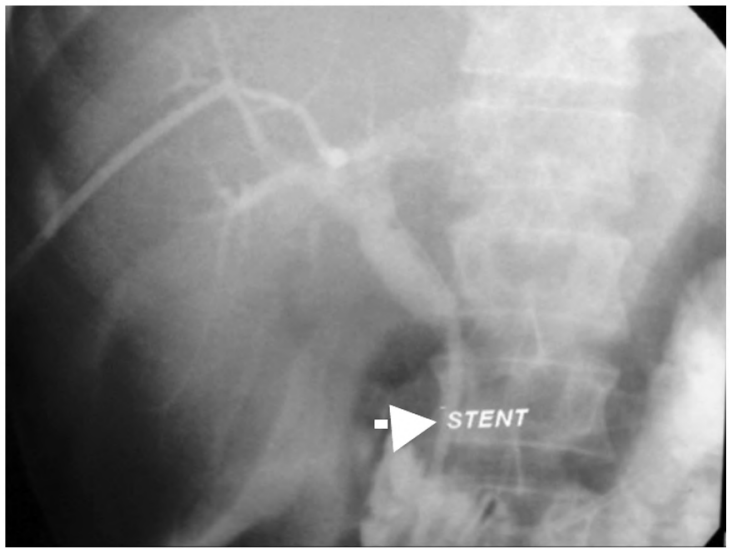

(F)

Fig. (5): (A): Ultrasound showed dilated biliary radical more prominent on the right side (arrow). (B): Coronal reformatted CT study showed duodenal mural wall thickening attenuating its lumen (arrow) and encroaching upon distal end of CBD with subsequent extra and intra hepatic biliary dilatation. (C): PTC was done via right duct showing distal CBD stricture (arrow) with dilated IHBR and CBD. (D): Guide wire reached the duodenum (arrow). (E): A balloon is seen dilating the stricture to facilitate stent placement (arrow). (F): Stent in place (arrow). 
Fig. No. (6):

- Male patient aged 56 years old diagnosed to have hilar cholangiocarcinoma kelat skin tumour.

- Total bilirubin level reached $31 \mathrm{mg} / \mathrm{dl}$.

- Bilateral right sided internal external drainage and left sided external drainage was done.
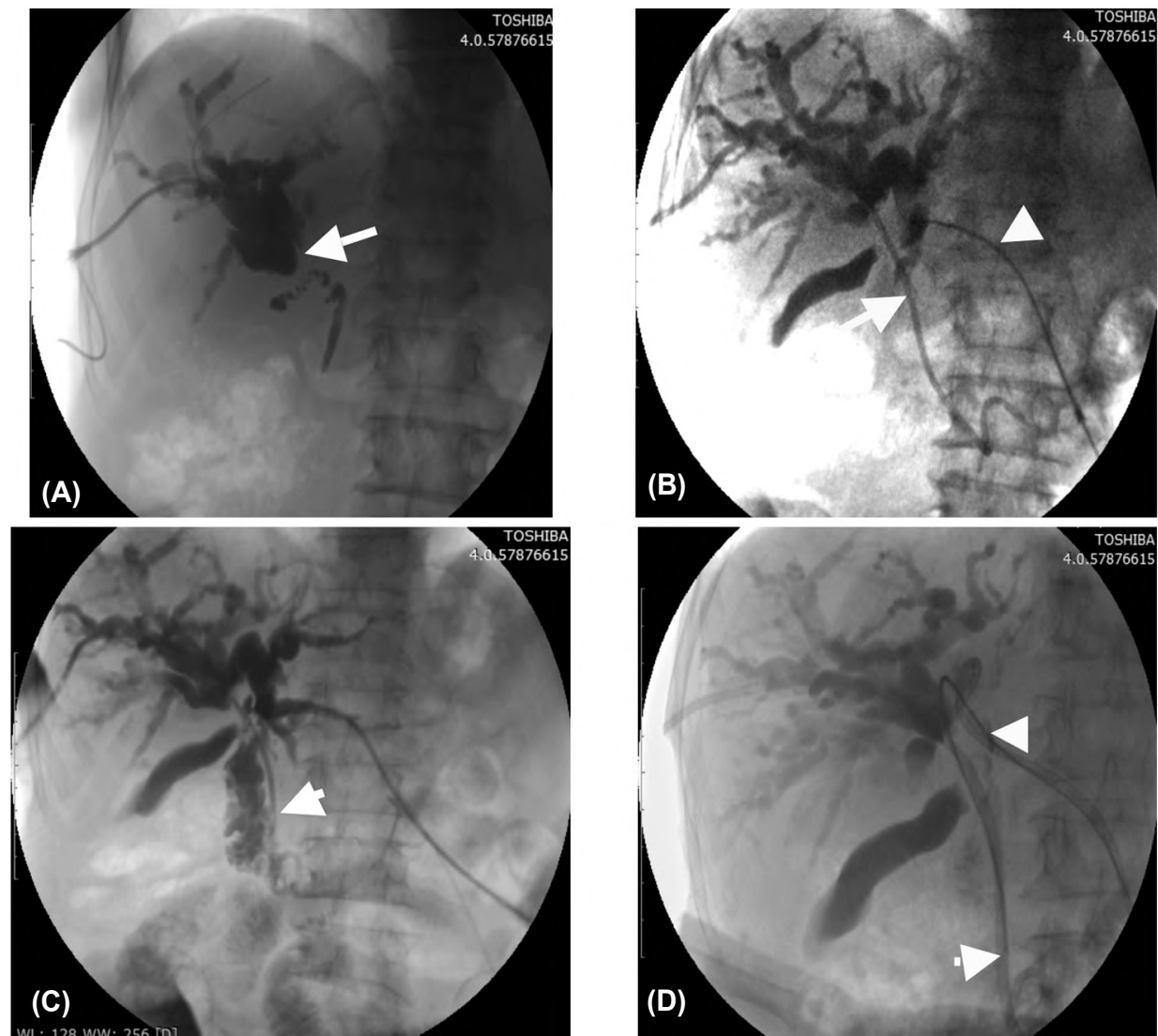

Fig. (6): (A): PTC through right duct approach revealed abrupt cut off of the contrast seen at the hilar region (arrow). (B) $10 \mathrm{~F}$ pigtail catheter seen passesd through the stricture into the duodenum (arrow) and left duct approach was achieved (arrow head). (C) Free passage of the contrast through the stricture into the duodenum (arrow). (D) Right internal external drain in place (arrow) and left external drain in place (arrow head).

Fig. No. (7):

- Male patient 57 years old diagnosed to have distal CBD Cholangiocarcinoma.

- Failed previous ERCP trial.

- Total bilirubin level reached $27 \mathrm{mg} / \mathrm{dl}$.

- Combined technique (Randez vous) was done for the patient.
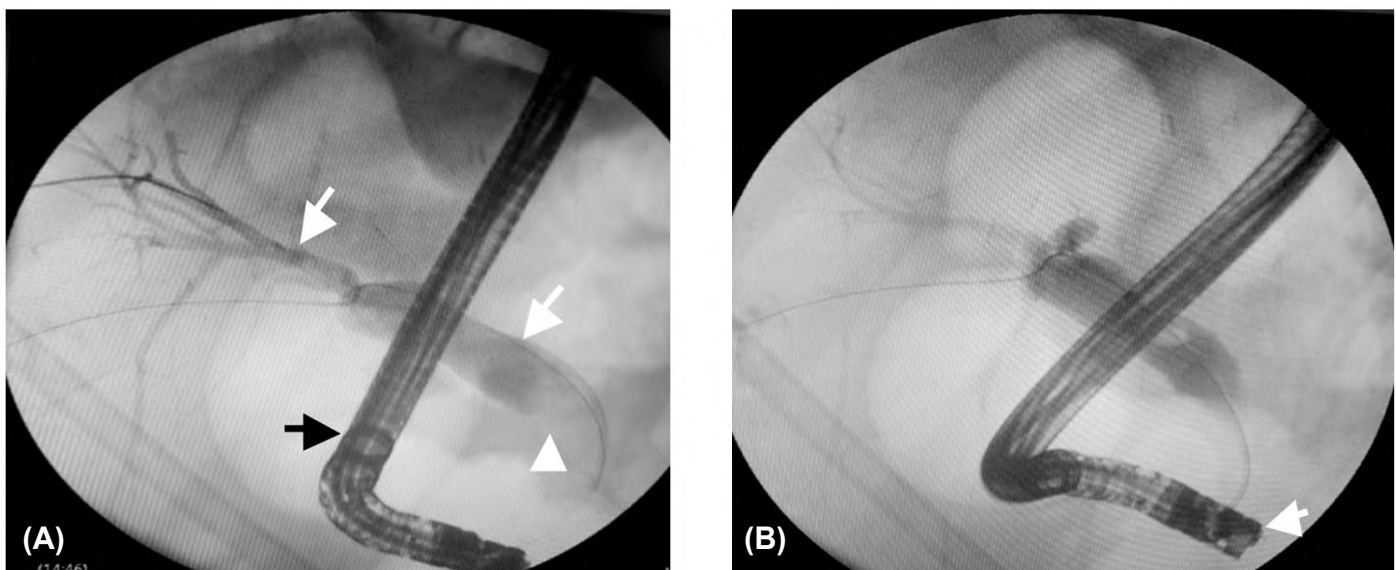

Fig. (7): (A): PTC through right duct approach showed dilated IHDR and CBD (arrows) with abrupt cut off (arrow head) with no contrast detected beyond and the endoscopic tube (black arrow) was seen with no access to the stricture site. (B): Wire was successfully passed through the stricture and caught by the snare of the endoscopic tube (arrow). 
Fig. No. (8):

- Male patient 64 years old diagnosed to have distal CBD cholangiocarcinoma.

- Total bilirubin level reached $15 \mathrm{mg} / \mathrm{dl}$.

- Metallic biliary stenting by a $10 \mathrm{~mm}$ diameter and $94 \mathrm{~mm}$ length self-expanding metal stent was done.
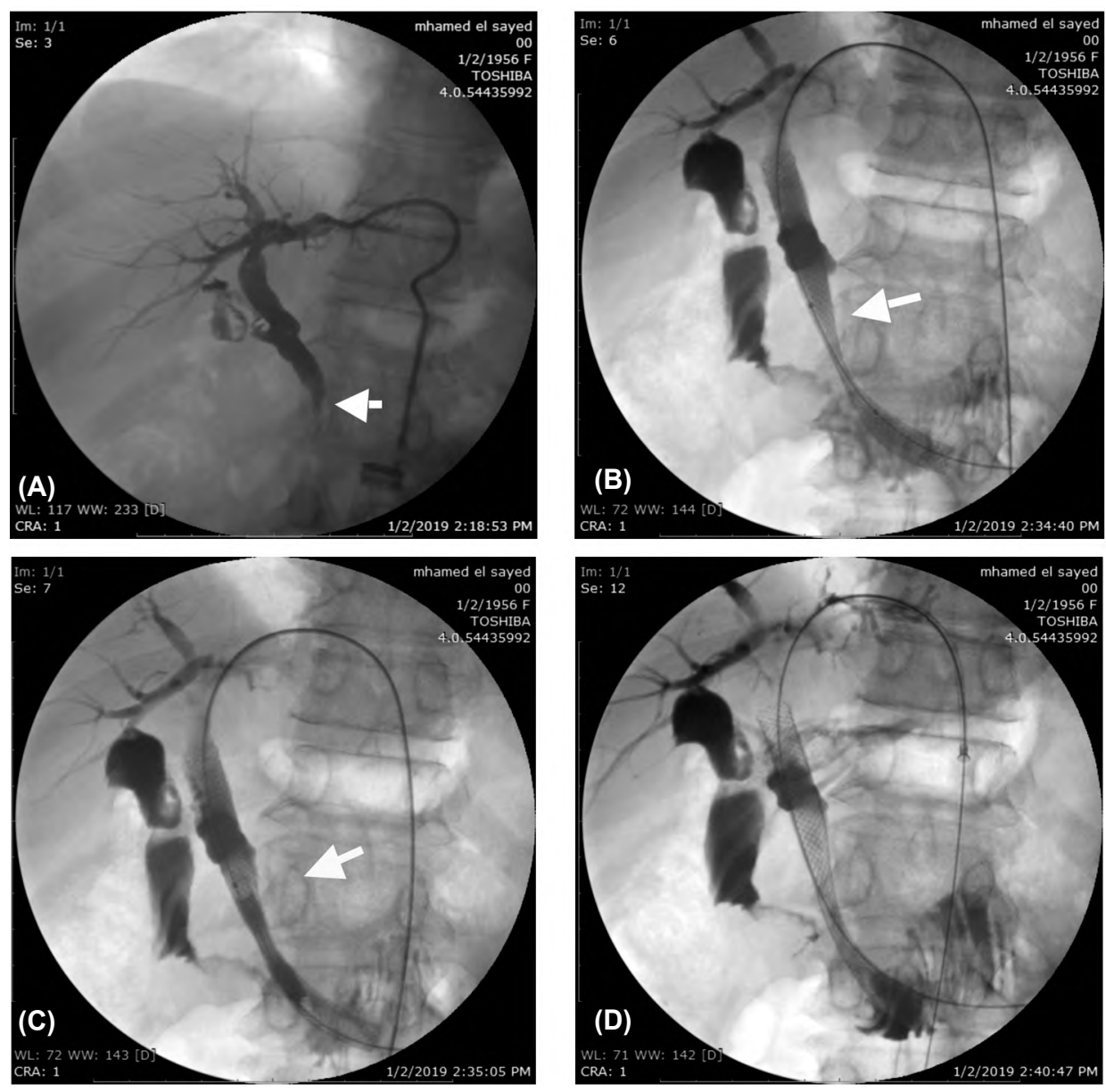

Fig. (8): (A): PTC was done via left duct approach showing distal CBD stricture (arrow) with mildly dilated IHBR and CBD. (B): A $10 \mathrm{~mm}$ diameter and $94 \mathrm{~mm}$ length self-expanding metal stent was inserted (arrow). (C): A 10mm diameter and $40 \mathrm{~mm}$ length balloon is seen dilating the stricture sites in the stent. (D): Stent in place (arrow) and there is free flow of contrast through the stent.

\section{Discussion}

Patients with malignancies affecting the biliary tree have poor prognosis and median survival of only 3-10 months [8].

Although endoscopic stenting is the procedure of choice, yet negotiation of malignant stricture in a retrograde fashion is not always possible. Hence, for patients in whom a primary endoscopic approach fails, percutaneous stenting, either directly or using combined percutaneous endoscopic procedure, is considered [9].

Our results support this opinion as endoscopic approach (ERCP alone) failed to bypass the stricture with 15 patients were successfully stented by percutaneous stenting with success rate $89 \%$.
Percutaneous trans hepatic bile drainage as a palliative procedure is well tolerated by patients, and after stenting, radiotherapy treatment for local tumor may prolong the duration of stent patency and the survival of patients. A disadvantage of the percutaneous trans hepatic approach is that the catheter must be left in place to act as a haemostat at the insertion site of the liver. However, this is also a benefit as the catheter could then be used to confirm the stent patency and to flush the metallic stent free from coagula or debris for 2 or 3 days post-procedure [10]

Stricture crossing was attempted and succeeded in 18 patients were managed as follows:

- In 8 patients, percutaneous metallic stenting were applied. 
- In 7 patients, percutaneous plastic stents were inserted, and

- In 3 patients, internal external drainage was done.

From the above mentioned data, the technical success rate of percutaneous stricture crossing and stenting was $13 / 15(81.2 \%)$. This result is higher than that mentioned in the study of Pinol et al., [18] who reported technical success rate of $75 \%$ for percutaneous metallic stenting. On the other hand, Schoder et al., [19] and Inal et al., [20] reported $100 \%$ technical success rate for percutaneous metallic stenting. This difference may be due to the variability of personal experience or the degree of tightness of biliary obstruction and tumour infiltration.

In the patients who were fit for operation (Whipple) with post-operative choledocho-jujenostomy biliary stricture, metallic stenting showed high success rate in reduction of bilirubin level and its related complications.

In the current study, 8 of the percutaneously drained patients showed significant reduction of total bilirubin. Accordingly, the therapeutic success of percutaneous drainage as a whole was $7 / 10$ $(70 \%)$.

There were significant clinical advantages for the metallic stents over plastic stents. Less occlusions occur in metallic stents with wider calibre. So, despite the higher initial expense of the metallic stent, a cost benefit advantage results from the reduced need for subsequent intervention. This is the same conclusion reached by many investigators like Carr-Locke et al., [23], Schmassmann et al., [24] and Kaassis et al., [25].

This advantage of metallic over plastic stent is valuable only when the patient is expected to survive for a relatively long period (6 months). Conio et al., [26] mentioned several prognostic factors as absence of liver metastasis, tumour size less than $3 \mathrm{~cm}$, stricture less than $2 \mathrm{~cm}$ and bilirubin less than $3.2 \mathrm{mg} / \mathrm{dl}$. These parameters should be considered when thinking to insert a metallic stent.

Among different groups in our study the lowest mean total bilirubin level 15 days after drainage was achieved with metallic stenting $(3.8 \mathrm{ng} / \mathrm{ml})$, while the highest mean total bilirubin level 15 days after drainage was seen in percutaneous external drainage $(10 \mathrm{ng} / \mathrm{ml})$, this can be explained in part by the wide calibre and high flow rates of metallic stents and in part by the fact that many patients who underwent external drainage presented with metastasis or liver cirrhosis increasing the mean of post drainage bilirubin.

Our results are in accordance with Pinol et al., [18] who found that the mean total bilirubin 15 days after drainage was $7.8 \mathrm{mg} / \mathrm{dl}$ for the endoscopic group and $5.2 \mathrm{mg} / \mathrm{dl}$ for the percutaneous metallic stent group.

In 30 patients underwent biliary drainage, complications occurred in 6 patients $(20 \%)$. This percentage is lower than that reported by Indar et al., [22] who found that early overall complications occurred in $30 \%$ of patients.

The study has three limitations. First, the limited numbers of patients involved in this study. Second, lack of financial support altered the decision for some cases and the last one was technical in two cases who intubation of the dilated biliary radical failed because of repeated trails.

\section{Conclusion:}

Finally, we can say that interventional radiology offers a great benefit for patients with malignant biliary obstruction in the term of symptomatic relief thus improving the quality of life.

\section{References}

1- ISAYAMA H., NAKAI Y., TOGAWA O., et al.: Covered metallic stents in the management of malignant and benign pancreatobiliary strictures. J. Hepatobiliary Pancreat. Surg., 16: 624-7, 2009.

2- GLAS L., COURBIÈRE M., FICARELLI S., et al.: Longterm outcome of percutaneous trans hepatic therapy for benign bilioenteric anastomotic strictures. J. Vasc. Interv. Radiol., 19: 1336-43, 2008.

3- HANNESSON P.H., SANDBERG A., STRIDBECK H., et al.: Treatment of malignant biliary obstruction by percutaneous transhepatic insertion of expomdable metallic stents, 2013, European Radiology, 5: 1-5, 2013.

4- HAUSSEGGER K.A., THURNHER S., BODENDORFER G., et al.: Treatment of malignant biliary obstruction with polyurethane-covered Wallstents. A.J.R., 403-8, 2014.

5- HAWKIN IRVIN F.: New fine needle for cholangiography with optional sheath for decompression. Radiology, 131: 252-3, 2010.

6- HELMS CLYDE A. and WILLIAM E. BRANT: Fundamentals of Diagnostic Radiology. Williams \& Wilkins, Maryland, p. 682, 2003.

7- HOEVELS J.: Percutaneous transhepatic cholangiography and percutaneous biliary drainage. In: Interventional radiology. In: Donlinger R.F., Rossi P., Kurdziel J.C. and Wallace S. (Eds). Georg \& Thiemen Verlag. Stuttgart. New York, p. 187-99, 2011.

8- HOEVELS J. and LUNDERQUIST A.: Techniques of percutaneous bile drainage. In: Non surgical biliary drainage, Classen M., Geeneb J. and Kawai K. (Eds) Springer 
Verlag. Berlin, Heidelberg New York, Tokyo, Ch. 4, p. 23-8, 2014.

9- HUIBREGTSE K.: The wallstent for malignant biliary obstruction Gastrointestinal Endoscopy Clinics of North America, p. 1402-11, 2008

10- BROUNTZOS E.N., PTOCHIS N., PANAGIOTOU I., et al.: A survival analysis of patients with malignant biliary strictures treated by percutaneous metallic stenting. Cardiovasc Intervent Radiol., 30: 66-73, 2007.

11- AHN S.J., BAE J.I., HAN T.S., et al.: Percutaneous biliary drainage using open cell stents for malignant biliary hilar obstruction. Korean J. Radiol., 13: 795-802, 2012.

12- RAY C.E., LORENZ J.M., BURKE C.T., et al.: ACR Appropriateness Criteria radiologic management of benign and malignant biliary obstruction. J. Am. Coll Radiol., 10: 567-74, 2013.

13- SANGCHAN A., KONGKASAME W., PUGKHEM A., et al.: Efficacy of metal and plastic stents in unresectable complex hilar cholangiocarcinoma: A randomized controlled trial. Gastrointest. Endosc., 76: 93-9, 2012.

14- LAMERIS J.S., STOKER J., NIJS H.G., et al.: Malignant biliary obstruction: Percutaneous use of self-expandable stents. Radiology, 179: 703-7, 1991.

15- SACKS D., McCLENNY T.E., CARDELLA J.F., LEWIS C.A.: Society of Interventional Radiology clinical practice guidelines. J. Vasc. Interv. Radiol., 14: S199-202, 2003.

16- DUMONCEAU J.M., TRINGALI A., BLERO D., et al. Biliary stenting: Indications, choice of stents and results: European Society of Gastrointestinal Endoscopy (ESGE) clinical guideline. Endoscopy, 44: 277-98, 2012.

17- PINOL V., CASTELLS A., BORDAS J.M., et al.: Percutaneous self-expanding metal stents versus endoscopic polyethylene endoprostheses for treating malignant biliary obstruction: Randomized clinical trial. Radiology, 225: 27-34, 2012.

18- SCHODER M., ROSSI P., UFLACKER P., et al.: Malignant Biliary Obstruction: Treatment with ePTFE-FEP- covered Endoprostheses-Initial Technical and Clinical Experiences in a Multicenter Trial, Radiology, 225: 3542, 2002.

19- INAL M., AKGUL E., AKSUNGUR E., et al.: Percutaneous self-expandable uncovered metallic stents in malignant biliary obstruction. Complications, follow-up and re intervention in 154 patients. Acta Radiol., 44: 139-46, 2003.

20- MAZZA E., CARMIGNANI L., STECCO A. and LUCIBELLO P.: Interventional radiology in the palliative treatment of pancreatic cancer, Eur. J., S54-9, 2002.

21- INDAR A.A., LOBO D.N., GILLIAM A.D., et al.: Percutaneous biliary metal wall stenting in malignant obstructive jaundice. Eur. J. Gastroenterol. Hepatol., 15: 915-9, 2003.

22- CARR-LOCKE D.L., BALL T.J. and CONNORS P.J.: Multicenter randomized trial of Wallstent biliary endoprothesis versus plastic stents, Gastrointest. Endosc., 39: 310,2010 .

23- SCHMASSMANN A., VON GUNTEN E., KNUCHEL J., SCHEURER U., FEHR H.F. and HALTER F.: Wallstents versus plastic stents in malignant biliary obstruction: Effects of stent patency of the first and second stent on patient compliance and survival. Am. J. Gastroenterol., 91: 654-9, 2008.

24- KAASSIS M., BOYER J., DUMAS R., et al.: Plastic or metal stents for malignant stricture of the common bile duct? Results of a randomized prospective study. Gastrointest. Endosc., 57 (2): 178-82, 2003.

25- CONIO M., DEMARQUAY J., DELUCA L., MARCHI S. and DUMAS R.: Endoscopic treatment of pancreaticobiliary malignancies, Oncology Hematology, 37: 127-35, 2011.

26- DAVIDS P.H.P., GROEN A.K., RAUWS E.A.J., et al.: Randomised trial of self-expanding metal stents versus polyethylene stents for distal malignat biliary obstruction. Lancet, 340: 1488-92, 2013

\section{دور الآثعة التداخلية والتصوير الطبى فى علاج مرضى إرتفاع الصفراء الإنسدادى بسبب آورام سرطية عانية مرضية}

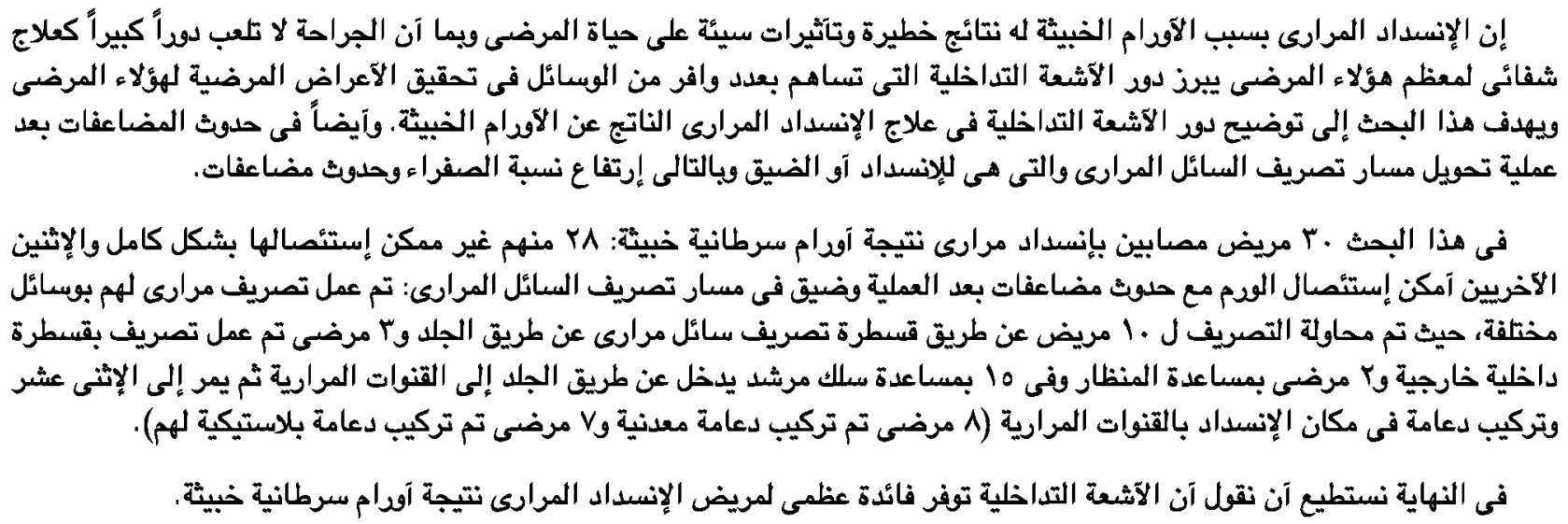

